\title{
Fatigue damage accumulation and lifetime prediction of defective C35 steel subjected to block loading
}

\author{
Haifa Sallem $^{1,3, a}$, Yves Nadot ${ }^{2}$ and Chokri Bouraoui ${ }^{1}$ \\ ${ }^{1}$ ENI-Monastir, Laboratoire de Génie Mécanique, Rue Ibn El Jazzar 5000 Monastir, Tunisie \\ ${ }^{2}$ ENSMA, Laboratoire de Mécanique et de Physique des Matériaux, 86961 Futuroscope, France \\ ${ }^{3}$ ENISE, Laboratoire de Tribologie et Dynamique des Systèmes, 42023 Saint-Etienne, France
}

\begin{abstract}
This paper deals with the influence of both defect and loading sequence on fatigue damage accumulation of C35 steel containing artificial defects. Tests were carried out using fatigue samples with artificial spherical defects introduced at the surface. Tests were performed using two blocks loading under increasing and decreasing magnitude. The experimental results were compared to the damage calculated by the Miner rule. In the case of defective material; it is shown in both cases a minor influence of sequence's effect. A lifetime prediction method is then developed to assess the residual lifetime of damaged defective material. The method is based on a multiaxial endurance criterion used to calculate the equivalent local stress distribution around the defect and to inject it in an uniaxial damage cumulative rule. Finally a comparison between experimental and theoretical results is performed. It is observed that the Mesmacque sequential law gives the most accurate lifetime prediction of defective specimens.
\end{abstract}

\section{Introduction}

Several approaches have been proposed to determine fatigue behavior of material with introduced defect [1]. But the effect of these defects on fatigue behavior has usually been evaluated by constant amplitude stress-life fatigue tests. However in service conditions, most engineering components are subjected to variable amplitude cyclic load. On the other hand different relationships have been proposed to estimate the effect of variable amplitude loading conditions on lifetime prediction, but only in the case of free defect material $[2,3,4]$. The present study deals with defective material. The objective is to study the influence of both defect and loading sequence on fatigue damage accumulation. The residual lifetime assessment is the most appropriate mean to reveal the effect of both defect and loading sequences.

\section{Experimental study}

Specimens are made from C35 carbon steel. Surface artificial spherical defects with controlled size have been machined at the middle of the gauge length of fatigue samples using electric discharge machining (EDM). Defect size is characterized by Murakami's parameter [5]: $\sqrt{\text { area }}=350 \mu \mathrm{m}$. Fatigue limits were determined for this size of defect (traction: $\sigma_{-1}=170 \mathrm{MPa}$ and torsion: $\tau_{-1}=145$ $\mathrm{MPa}$ ). Then fatigue tests under blocks of cyclic loading with increasing and decreasing amplitudes are

\footnotetext{
${ }^{\mathrm{a}}$ Corresponding author: sallem.haifa@hotmail.fr
} 
performed (stress ratio $\mathrm{R}=-1$ ). The structure is initially damaged at a given load amplitude level and for a number of cycles denoted $n_{1}$. The fatigue tests are then pursued until failure $\left(n_{2}\right)$. The results are shown in Figure 1. $N r_{1}$ and $N r_{2}$ are respectively the number of cycles to failure corresponding to each block loading (S-N Curve).
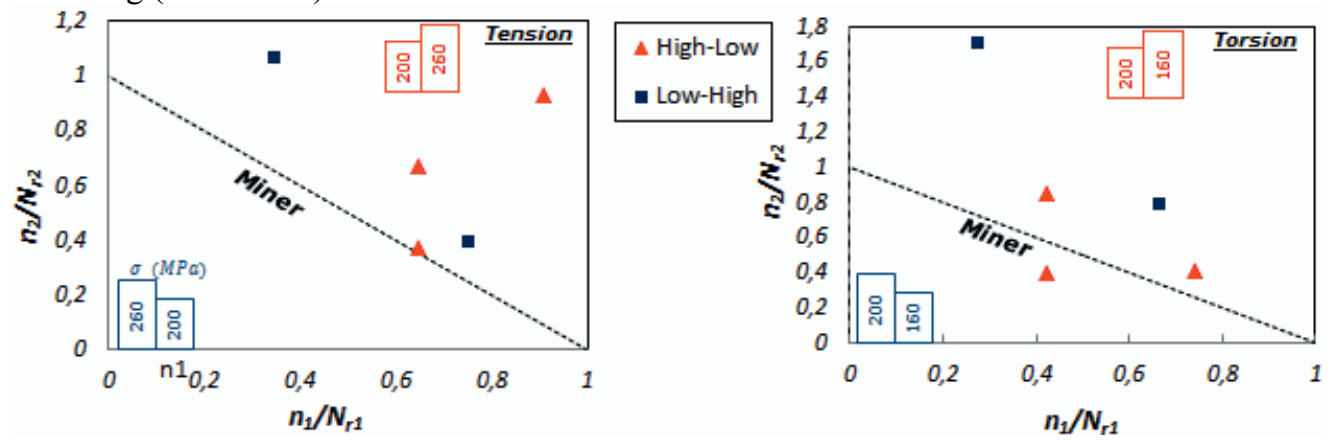

Figure 1.Experimental lifetimes of all two-block fatigue tests compared to miner law: tension and torsion.

These results are contrary to the trend observed for defect free C35 steel specimens for the same type of loading sequences [6]. In fact effect of the defect clearly appears: for two loading cases, the experimental life ratio corresponding to the second block is much greater than the ratio predicted using the Miner law and sometimes greater than S-N curve when $\left(n_{2} / N_{r 2}>1\right)$. A propagation delay of the crack is thus suspected.

\section{Prediction of the residual lifetime}

To predict residual lifetime for material with defect, finite element calculation of structure was performed to investigate the stress distributions around the defect. Then equivalent stress around defect $\sigma_{\text {eqv }}^{*}$ taking into account the multiaxial stress fields as well as the gradient effect was determined using multiaxial fatigue criterion for surface defective materials [1] (Fig. 2 (a)) .As a result a couple $\left(\sigma_{\text {eqv }}^{*}, N_{r}\right)$ was identified instead of $\left(\sigma, N_{r}\right)$ and then an equivalent $\boldsymbol{S}$ - $\boldsymbol{N}$ curve $\left(\sigma^{*}\right.$ eqv,$\left.N_{r}\right)$ was drawn up. Finally, common cumulative damage rules for free defect material based on indicators determined from the Whöler S-N curve was used such as: Miner's law [2] Lemaitre's law [3] and Mesmacque's law[4]. Results show better accordance to experimental data especially for traction loading with Mesmacque's law (Fig. 2 (a)).
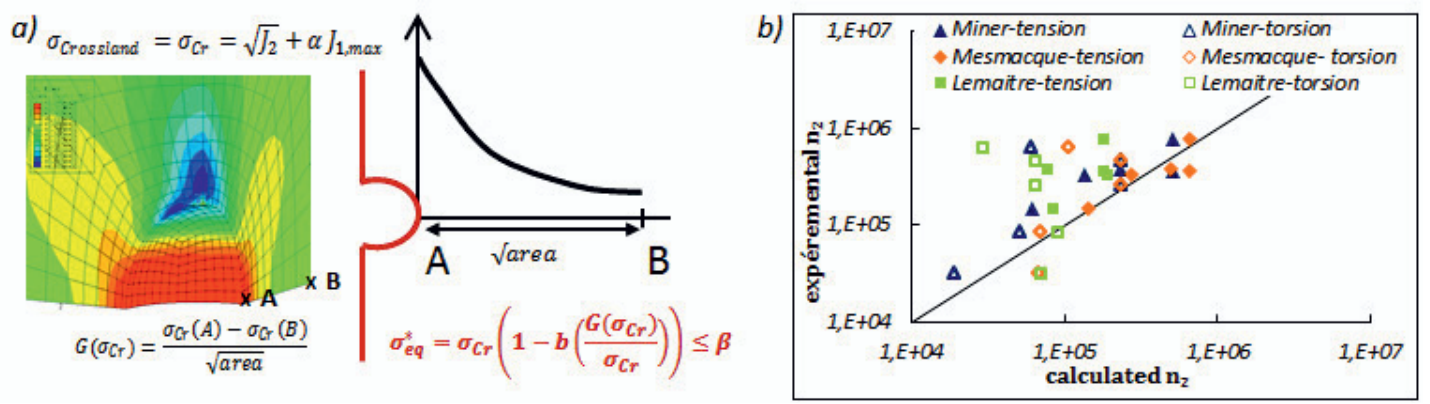

Figure 2. (a) Stress distribution around the defect (b) Parity diagram for residual life cycle $\mathrm{n}_{2}$

\section{References}

1. Y. Nadot, T. Billaudeau, EFM 73, 22 (2006)

2. M.A. Miner, J. Appl. Mech 159, 6 (1945)

3. J.Lemaitre, J.L. Chaboche, Mécanique des matériaux solides (1988).

4. G. Mesmacque, S. Garcia, A. Amrouche, C. Rubio-Gonzalez, IJF 27, 7 (2005)

5. Y. Murakami, Metal fatigue: effects of small defects and nonmetallic inclusions, 66 (2002)

6. N.Huyen, F.Morel, colloque national MECAMAT, 5 (2007) 